\title{
A BNCC e o "novo" Ensino Médio: reformas arrogantes, indolentes e malévolas
}

\author{
The BNCC and the "new" High School:
}

arrogant, indolent, and malevolent reforms

\section{La BNCC y la "nueva" Escuela Secundaria: reformas arrogantes, indolentes y malévolas}

\author{
MARIA LUIZA SÜSSEKIND* \\ Universidade Federal do Estado do Rio de Janeiro, Rio de Janeiro- RJ, Brasil.
}

\begin{abstract}
RESUMO: Desloca-se o debate sobre as reformas atuais da educação básica em revisita a tensões do campo, sob o argumento de que a ideia de um currículo escriturístico como projeto de naçãoé um modo de produção epistemicida. Partimos da percepção de que o modo de conhecer moderno engendra também suas ignorâncias e aponta, em diálogo com as teorias de Boaventura Santos, que a reforma é arrogante, indolente e malévola, produz injustiças, invisibilidades e inexistências. Na direção do Sul epistemológico, conclui-se que o conhecimento curricular democrático é deslocamento, conversa, e resistência ao pensamento único.
\end{abstract}

Palavras-chave: Currículos. BNCC do Ensino Médio. Epistemologias do Sul.

\begin{abstract}
The debate on current reforms of basic education is revisited in the field tensions, under the argument that the idea of a scriptural curriculum as a nation project is an epistemic form of production. We start from the perception that the modern way of knowing also engenders its ignorance and points out, in dialogue with the theories of Boaventura Santos, that the reform is arrogant, indolent and malicious, produces injustices, invisibilities and non-existences. Heading
\end{abstract}

* É Doutora em Educação pela Universidade do Estado do Rio de Janeiro e Professora no PPGEdu/Unirio. Atua como líder do Grupo de Pesquisa Práticas educativas e Formação de Professores (GPPF) e é editora da Revista Teias (Proped-UERJ). E-mail:<luli551@hotmail.com>. 
to the epistemological South, one concludes that the democratic curricular knowledge is displacement, conversation, and resistance to the unique thought.

Keywords: Resumes. High School BNCC. Epistemologies of the South.

RESUMEN: Esta investigación desplaza el debate sobre las reformas actuales de la educación básica al revisitar las tensiones del campo, argumentando que la idea de un currículo escriturístico como proyecto de nación es un modo de producción epistemicida. Partimos de la percepción de que el modo moderno de conocer engendra también sus ignorancias y muestra, en diálogo con las teorías de Buenaventura Santos, que la reforma es arrogante, indolente y malévola, produce injusticias, invisibilidades e inexistencias. Hacia el sur epistemológico, se deduce que el conocimiento curricular democrático es el desplazamiento, el diálogo y la resistencia al pensamiento único.

Palabras clave: Currícula. BNCC de la Escuela Secundaria. Epistemologías del Sur.

\section{Introdução}

E ste artigo tem o objetivo deslocar o debate sobre as políticas de currículo e reformas atuais para educação básica numa direção de revisita à conformação e tensões do campo, argumentando que a ideia de um currículo escriturístico como projeto de nação tem pautado os debates e é um modo de produção epistemicida. Partindo da percepção de que o modo de conhecer moderno engendra também suas ignorâncias e, assim, produz injustiças, aponta, em diálogo com as teorias de Boaventura de Sousa Santos, que a BNCC é arrogante, indolente e malévola, e, com suas ignorâncias, produz injustiças, invisibilidades e inexistências, coisificando os conhecimentos, ferindo a autonomia, desumanizando o trabalho docente e, ainda, descaracterizando o estudante na sua condição de diferente, de outro legítimo. Na direção do Sul epistemológico ${ }^{1}$, lutando contra o assassinato dos conhecimentos, das experiências, da vida e dos acontecimentos, conclui que o conhecimento curricular que se deseja democrático é deslocamento e conversa, é resistência permanente ao pensamento único, homogêneo, unívoco, uníssono, não é comum, é diferença e é dissenso.

“a razão displicente que não sente necessidade de se exercitar por se imaginar incondicionalmente livre" (SANTOS, 2001, pág. 42). 
Tenho chamado atenção, junto a diversos autores e em escritos anteriores, sobre um modo displicente e preguiçoso de pensar e praticar as políticas de conhecimento, e as políticas curriculares (OLIVEIRA; SÜSSEKIND, 2017, 2018, 2019; SÜSSEKIND, 2014a; 2014b; 2017; SÜSSEKIND; PELLEGRINI, 2016a; 2016b). Displicente e preguiçoso porque, segundo entendemos a partir da obra de Santos (2001, 2004, 2005, 2006, 2010, 2013, 2019), o modo de produção de conhecimento é monocultor, sendo assim, baseia-se numa razão indolente, que tem preguiça de reconhecer outros modos e outras experiências de conhecimento, anulando a pluralidade do mundo e a diferença ontológica que nos torna humanidade. Assim, dominado pela preguiça de reconhecer o "outro", o conhecimento que se configurou como ocidental, eurocêntrico, capitalista, colonial, branco e heteropatriarcal e se tornou hegemônico tem uma razão indolente. De modo displicente e arrogante arvora-se de tal superioridade que se reconhece único, melhor, total e, até mesmo, neutro. Torna-se não só hegemônico, mas único.

A razão indolente é poderosa, embora impotente e, em sua forma de monocultura, produz invisibilidades, inexistências, sendo epistemicida na sua condenação do outro ao abismo. Ela precisa ser vista em sua contraditória face impotente, já que, ao não dar conta de perceber nem resolver os problemas complexos de um mundo plural, foi se tornando assim arrogante, por ser também metonímica e proléptica. Esse modo de produção de conhecimentos é monocultor, baseando-se na opressão e no aprisionamento monolítico de outras maneiras pelas quais é possível tecer outros conhecimentos. É abissal, eurocêntrico, colonial, escravocrata, heteropatriarcal... Assim, a arrogância acaba sendo inerente à razão indolente assim como impotência, prolepsia e metonímia que a acompanham.

A razão metonímica se percebe como a única forma de racionalidade possível. Logo, ela é obcecada pela primazia do todo sobre as partes, subentendida na própria ideia de totalidade pela qual leva a conviç̧ão que há apenas uma lógica que governa os comportamentos tanto do todo quanto de cada uma de suas partes, e à homogeneização todo/parte (OLIVEIRA, 2006).

Sendo indolente, a razão é arrogante e impotente, bem como metonímica, porque, ao tomar a parte pelo todo, ela contrai, diminui, subtrai o presente e suas ações, não nos permitindo ter uma visão ampla desse. Assim sendo, quando exercida sobre as práticas sociais, ela cria a noção de que tudo e todos se configuram em apenas uma totalidade, como se fôssemos uma humanidade homogeneizada e, portanto, tivéssemos características simétricas e lineares.

Sem admitir que, diante da complexidade do social, o todo não é a soma das partes como não representa a soma de todas nelas e, inclusive, sem admitir que o todo é também uma parte, a razão indolente faz operações metonímicas e cria espelhos que de modo arrogante obnubilam a riqueza e os acontecimentos do mundo da vida, plural, local e inédita. Em outro movimento abissal e colonizador da possibilidade de copresença, o pensamento racional moderno europeu ou o Norte Global engole os presentes 
e os afunila em uma única possibilidade (e linearidade) de futuro. Apontando em demasia para o futuro, apaga o presente e suas possibilidades de conhecimento, democracia e emancipação. Teleológico, proléptico, o pensamento abissal desperdiça, junto com o presente, suas possibilidades de existência, criação e resistência.

O pensamento ocidental moderno é um pensamento abissal. Consiste em um sistema de distinções visíveis e invisíveis, sendo os invisíveis a base dos visíveis. As distinções invisíveis são estabelecidas através de linhas radicais que dividem a realidade social em dois reinos, o reino de "este lado da linha" e o reino do "outro lado da linha". A divisão é tal que "o outro lado da linha" desaparece à medida que a realidade se torna inexistente e é de fato produzida como inexistente. (...) O que mais fundamentalmente caracteriza o pensamento abissal é, portanto, a impossibilidade da co-presença dos dois lados da linha (SANTOS, 2010, p. 23-24).

\section{O pensamento abissal}

\section{"A ciência eurocêntrica se encerrou no século XX" (HOBSBAWN, 1995, p. 505).}

A tradição científica do Norte hegemônico dá sentido ao mundo por meio de ideias gerais e conceitos universais, que são cada vez menos convincentes como sendo globalmente adequados, politicamente corretos ou, simplesmente, como sendo uma boa forma de entendimento. Tendo sido por mais de uma década professora de história na educação básica, corro o risco de dizer que os fenômenos sociais sempre assombraram a Ciência, enfrentando a colonização da pesquisa do humano e do social pelas ciências da natureza e a marginalização dos conhecimentos que não se adequavam aos padrões científicos, como o feminismo, a psicanálise, a antropologia etc. Hoje em dia, a Ciência também é assombrada por inovações do Sul, movimentos e ocupações de estudantes, feministas, ambientalistas, entre outras transformações e práticas de cosmopolitismo emancipatório no tempo e online. que, para Boaventura Santos, se manifestam por vezes no rap, no Slam das Minas, na pichação e na internet.

Se pensamos que o mundo se tornou menos eurocêntrico é porque o "Norte global é cada vez menor", o que Boaventura explica através da escassez de conceitos globais e da falência do projeto de modernidade, também apontado por Giddens (1997) e Bauman $(1998 ; 1999)$ em seus trabalhos. Concordo com eles que as generalizações e os conceitos universais, também são cada vez menos convincentes. Neste sentido, o Norte tem menos a ensinar, e Santos explica que isso acontece porque se você não tem muito o que ensinar é porque parece que você também tem menos capacidade de aprender a partir do exterior.

Temos sugerido, então, que a primazia e credibilidade da Estatística alimentam um modelo preguiçoso e simplificador de entendimento do mundo que reflete apenas parte 
da realidade e "desperdiça a experiência" (SANTOS, 2001) do trabalho criativo dos professores e estudantes, aliando-se aos interesses mercadológicos para produzir as reformas educacionais em curso, construindo "hegemonia" de modo que o subalternizado sinta-se culpado pela sua abissalidade (SANTOS, 2013). No campo da educação, em meio a pesquisas e índices, sabemos que a ideia de que conhecer significa quantificar tem dominado metodologias e orientado políticas em que os números e os índices anulam a vida e o sangue que corre nas escolas. Isso é um modo bem arrogante de conhecer e que pouco captura daquilo que acontece nos chãos das escolas (SÜSSEKIND, 2017). "Trata-se de uma racionalidade indolente cuja indolência se traduz na ocultação ou marginalização de muita experiência e criatividade que ocorre no mundo e, portanto, no seu desperdício" (SANTOS, 2004, p. 53).

Argumentamos, ainda, que o lugar preponderante ocupado pela Matemática na Ciência Moderna, segundo Boaventura, terá, ainda, uma segunda consequência: “o método científico assenta na redução da complexidade" (SANTOS, 2001, p. 63). Pensar a educação a partir de números é acreditar que é possível compreender a realidade de um sistema educacional com um único olhar, que existe uma única realidade. Olhar este que invisibiliza a complexidade dos cotidianos das salas de aula e as localidades das redes educacionais espalhadas pelo Brasil para poder enxergá-las em grandes números (SÜSSEKIND, PRESTES, 2015). São mais de 203.000 escolas, logo, tomar a parte pelo todo não explica muito; e quem já entrou em uma escola sabe que seu todo não é mais que outra de suas partes. Mas, esta credibilidade está relacionada à crença que temos na relação entre medição, controle e, portanto, qualidade.

A ciência moderna não é a única explicação possível da realidade e não há sequer qualquer razão científica para a considerar melhor que as explicações alternativas da metafísica, da astrologia, da religião, da arte ou da poesia. A razão por que privilegiamos hoje uma forma de conhecimento assente na previsão e no controlo dos fenômenos nada tem de científico. É um juízo de valor. A explicação científica dos fenômenos é a auto-justificação da ciência enquanto fenômeno central da nossa contemporaneidade. A ciência é, assim, autobiográfica (SANTOS, 1987, p. 52).

Ao nos mirarmos em espelhos, sobretudo aqueles construídos pela Ciência, autobiográfica, arrogante e indolente, enxergamos sua maldade. Tentando tomar o lugar da própria vida, fixados, vidrados, mesmerizados pela imagem do nosso próprio desejo, arrogantes, caímos no abismo como narciso ao contemplar-se (SÜSSEKIND, PRESTES, 2015) e desaparecemos. Espelhos que podem ser criados a partir da razão indolente e arrogante, como nos índices Ideb, Enem, ANA, Pisa etc., imagem que tem preguiça de reconhecer a pluralidade e a diversidade, sendo indolente. Imagens que apagam a diversidade e a hierarquizam de modo arrogante. Assim divulgam, classificam as escolas, professores e estudantes, numa lógica malévola de espelhos fixos (SÜSSEKIND; PRESTES, 2015). No extremo da arrogância, a razão malévola pode produzir o que não existe 
como imagem de realidade, numa forma de ignorância arrogante, autoritária, ressentida e epistemicida, que se nutre do ódio e do aniquilamento da diferença. Assim, a razão

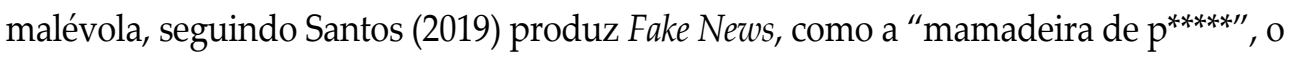
"kit gay" e o "golden shower".

Como aprendemos com a crítica da razão indolente, os espelhos organizam o mundo e geram conforto e segurança ontológicos, dividindo homens e mulheres, colonizadores e colonizados, civilização e barbárie, sempre hierárquica e indolentemente (SANTOS, 2001). Abissalmente, de modo epistemicida, para além dos espelhos, o que existe se torna desimportante, invisível ou inexistente (SANTOS, 2001, 2010).

Graças à investigação e à teoria feministas, sabe-se hoje que os espelhos, sendo um objeto de uso corrente desde há muitos séculos, são usados de modo diferente (...). São os espelhos que, ao criar sistemas e práticas de semelhança, correspondência e identidade, asseguram as rotinas que sustentam a vida em sociedade.

Há duas diferenças fundamentais entre o uso dos espelhos pelos indivíduos e pela sociedade. A primeira diferença é, obviamente, que os espelhos da sociedade não são físicos, de vidro. São conjuntos de instituições, normatividades, ideologias que estabelecem correspondências e hierarquias entre campos infinitamente vastos de práticas sociais. São estas correspondências e hierarquias que permitem reiterar identificações até ao ponto de estas se transformarem em identidades. A ciência, o direito, a educação, a informação, a religião e a tradição estão entre os mais importantes espelhos das sociedades contemporâneas. O que eles reflectem é o que as sociedades são. Por detrás ou para além deles não há nada.

A segunda diferença é que os espelhos sociais, porque eles são processos sociais, têm vida própria [...] (SANTOS, 2001, p. 47, 48).

Estamos tratando da capacidade de reproduzir ad aeternum o outro através de processos de construção de dicotomias (culturais e epistêmicas), que hierarquizam e assassinam muito do que existe entre o saber científico e os saberes alternativos, tomados como rivais. Desprovido de experiência e, assim, de existência, o Sul apenas pode existir como o lado de lá do manancial acumulado no Norte. Por isso, a Escola de Samba Mangueira, no carnaval de 2019, ao demandar outra história, que contemple Marias, Mahins, Marielles e Malês, quer um país que não está no retrato, já que foi tornado inexistente.

\footnotetext{
Não há uma maneira única ou unívoca de não existir, porque são vários as lógicas e os processos através dos quais a razão metonímica produz a não-existência do que não cabe na sua totalidade e no seu tempo linear. A produção de não-existência ocorre sempre que uma dada entidade é desqualificada e tornada invisível, ininteligível ou descartável de um modo irreversível (SANTOS, 2004, p. 787).
}

Portanto, a hegemonia do Norte, sustentada pelo domínio inquestionável da razão e pelo desrespeito do pensamento ocidental à experiência (SANTOS, 2001), afeta os currículos nas escolas. De acordo com Santos, a razão ocidental é preguiçosa e torna invisível o conhecimento da experiência, um desperdício de conhecimento humano... Isto se traduz 
num movimento perpétuo de invisibilização do conhecimento escolar, tratando-o como inexistente ou diferente, mas sempre inferior ao científico. Então, podemos dizer com Boaventura Santos que a cultura Norte-Ocidental, global, e a tradição hegemônica da Ciência (assim como o Direito Moderno) andam oferecendo explicações desatualizadas e insuficientes... Seria difícil não reconhecer que a crise da colonialidade e do eurocentrismo se relacionam de modo íntimo à profunda e irreversível crise do modelo de racionalidade científica (SANTOS, 2001, p. 68).

Entendo, ainda, com a teoria do pensamento abissal de Santos $(2007,2010,2013)$, que esta imagem dicotômica, em que o Norte é o centro do conhecimento científico, da cultura, da indústria e da tecnologia, não representa com precisão a "realidade atual" porque o mundo está aprendendo mais e mais a partir do $S u^{2}$. Sem dúvida, preciso reconhecer que esta ainda é uma nova abordagem epistemológica, que se define pelo compromisso político de emancipação social e pela crítica astuta e a inversão dos princípios da Ciência Moderna (SÜSSEKIND, 2007; 2012; também em PINAR, 2011).

Tomando as palavras de Santos como se costuram retalhos, a linha abissal pode ser invisível, mas sua presença é inequívoca quando se observa rigorosamente a organização social, os processos de validação dos conhecimentos e, sim, as práticas escolares cotidianas de conhecer, aprender e ensinar. Contra esta linha e sua exclusão para o abismo, as minorias - os colonizados, o Sul, todas as formas não-científicas de compreensão do mundo, os maus-alunos e os professores demonizados e culpabilizados por cegos modelos de análise - se levantam a favor de uma nova epistemologia pós-colonialista, cosmopolita. A desinvisibilização e a emergência apresentam-se como alternativa ao paradigma hegemônico (SANTOS, 2004), sendo lutas políticas e emancipatórias em todos os seus aspectos.

No debate sobre o papel desempenhado pela Ciência nos currículos das escolas e pelas pesquisas cientificas sobre a educação e sobre as escolas podemos reforçar, ou não, os movimentos de colonização, e reforçar, ou não, as ideias de currículo como lista de conteúdos e procedimentos esvaziados de histórias e subjetividades. Basta pensarmos na escola no singular, como modelo fixo, nas listas e hierarquias entre os conteúdos da BNCC, e no pacote de direitos e deveres do "novo" ensino médio que subalternizam estudantes tratando-os como objetos e não sujeitos do direito de aprender. Esse currículo é uma base, que aponta caminhos, resultados, trajetórias, conhecimentos esperados, competências e incompetências. É uma flecha que aponta certeira para um alvo final, ideal, irrealizável, inatingível que deixa montes de invisíveis, inexistentes e fracassados pelo caminho da construção da nação (BOBBIT, 1918).

Nesse sentido, desdobra-se o argumento no questionamento das políticas de currículo que se caracterizam como reformistas e conectam currículos e materiais didáticos unificados aos resultados dos testes externos padronizados e à formação para o mercado entendendo que desenham linhas abissais (SANTOS, 2007) apagando a diferença e abduzindo as experiências da criação cotidiana dos conhecimentos (SANTOS; 2001), escolares, sociais e outros (SÜSSEKIND; 2014a). Sendo 
assim, sob a promessa de iguais oportunidades de aprender (BNCC/2016/2017), realizam controle e cassam a autonomia do trabalho docente, descaracterizando a diferença em busca de mesmidade e contribuído para a crescente desigualdade dos sistemas educacionais. Tratam o ser humano como objeto de direitos e não sujeitos (SANTOS, 2013) do direito de aprender. Aponto que isso desvaloriza a aula abduzindo dos currículos sua principal característica que é ser uma criação cotidiana feita como conversa complicada, e ameaça a formação de professores e sua docência como trabalhadores-intelectuais. Por isso, coloca nosso trabalho e a própria democracia em risco (SÜSSEKIND, 2014a; ANPED; ABDC, 2015).

Como já argumentamos anteriormente (SÜSSEKIND, 2014a; 2014b; SÜSSEKIND; PELLEGRINI, 2016a; 2016b; 2017), as políticas curriculares propostas pelo Ministério da Educação, a BNCC que circulou em versões progressivamente reduzidas em conteúdos e áreas e pautadas pela desideologização e o "Novo Ensino Médio" trazem uma conceituação de currículo (e de comum) que parecem se constituir a partir de uma perspectiva de decifrar uma escrita não escrita, uma escrita de entendimento único, colonial e eurocêntrico. Assim, decifrar assume o sentido utilizado comumente, inclusive no campo da Ciência, de compreender uma realidade apriorística a partir de alguma teoria, ideia ou ferramenta poderosa. Isso faz com que, teoricamente, a BNCC e o "Novo EM" possam ser caracterizados como abissais, indolentes, metonímicos e prolépticos.

Defendendo que currículos são espaços-tempos de criação e tessituras de conhecimentos em redes, a partir de Nilda Alves (2001) ou, ainda, são as conversas complicadas de William F. Pinar (SÜSSEKIND, 2014c), que quase independentemente das disciplinas e planejamentos versam sobre cosmopolitismos, historicidades, subjetividades, alegorias e silêncios, argumentamos que a proposta de unificar currículos como forma de garantir o direito a aprendizagem (PNE/2014) por meio de objetivos elencados numa base (BNCC) prevê o controle dos processos de conhecer e do conhecimento produzido como negação a esse direito, sendo abissal e arrogante. E, pior, como sustenta que produzirá justiça e igualdade, é malévola.

A credibilidade devotada ao currículo como documento unificador e às testagens padronizadas como instrumento verificador e diagnóstico da aquisição de conhecimentos curriculares considerados essenciais para viver na sociedade sugere um entendimento escriturístico do texto, subestimando toda e qualquer interação social e, portanto, consequente negociação de sentidos, que envolve seu uso, conforme advogava Certeau (1994), e provoca o desperdício das experiências locais e enredadas nas subjetividades e conhecimentos das pessoas e da sociedade (SANTOS, 2001; ALVES, 2001). Propor um currículo que não é currículo, mas sim papel, lista, prescrição de significados, é propor aos professores que negociem com seus estudantes a criação de conhecimentos a partir de uma codificação arbitrária de significados, cobrados em testagens externas padronizadas. A escrita nunca escrita que deve ser decifrada no currículo como base (BNCC) é um currículo de previsibilidade, prescrição e controle de significados, sem vínculo com os 
currículos dos pensados/praticados nos cotidianos (OLIVEIRA, 2012, p. 11) pelos múltiplos sujeitos das escolas (SÜSSEKIND; PELLEGRINI, 2016a; 2016b). Por mais prescritivo que seja o documento curricular - e tanto a BNCC quanto o "Novo" EM projetam altíssimo nível de prescrição, controle, responsabilização de professores e gestores pelos resultados - pensamos que, nas conversas complicadas que são os currículos, os conhecimentos, os documentos curriculares trazem escritas sobrepostas, reutilizadas. São currículos-palimpsestos que, como pergaminhos, se decifram nas redes de conhecimentos e de tessitura dos conhecimentos, fazendo o caminho no andar (ALVES, 2008, p. 16). É a partir dessa proposta de complexidade e diferença que podemos compreender/interpretar o cotidiano escolar nunca a partir de uma ideia de realidade preexistente nem de distanciamento ou fixidez, já que somos fios dessas redes (SÜSSEKIND; PELLEGRINI, 2016a; 2016b). Ao se perguntar se e como é possível "transmitir" o que foi sendo apreendido/aprendido, Alves desdobra o problema ensinando que

é preciso uma outra escrita para além da já aprendida. Há assim, uma outra escritura a aprender: aquela que talvez se expresse como múltiplas linguagens (de sons, de imagens, de toques, de cheiros etc) e que, talvez, não possa ser chamada mais de "escrita"; que não obedeça à linearidade de exposição, mas que teca, ao ser feita, uma rede de múltiplos, diferentes e diversos fios; que pergunte muito além de dar respostas; que duvide do próprio ato de afirmar, que diga e desdiga... (ALVES, 2008, p. 30, 31; grifo meu)

Portanto, na ideia de Base, de prescrição de trajetórias eitinerários, há uma decifração prescritiva do resultado do conhecer (SÜSSEKIND; PELLEGRINI, 2016a; 2016b). Há essa escrita que nunca foi escrita porque não se recheia de experiência, desfaz do vivido. Desvaloriza o oral em nome de uma economia escriturística da palavra. Pensar estudantes e professores numa tarefa intelectual de reescrita da própria sociedade exige a refutação das "teses comuns sobre a passividade dos consumidores e a massificação dos comportamentos" (GIARD, 1994, p. 27) e nos impõe pensar os conhecimentos sempre no plural, considerando sua fabricação cotidiana e suas incontáveis possibilidades de usos (CERTEAU, 1994, p. 39). Mesmo uma atividade silenciosa que é a leitura "parece aliás constituir o ponto máximo da passividade que caracterizaria o consumidor" (p. 49) no contexto escriturístico em que o oral "não contribui para o progresso" (p. 224) e que, nos três últimos séculos, vincula à iniciação na sociedade capitalista à pratica da escrita (p. 227), sendo preciso "sentir os efeitos inquietantes de um tão prodigioso avanço para que suspeitássemos ser a formação da criança moderna uma prática escriturística" (idem). Mas Certeau (1994) adverte que o leitor será sempre impertinente (p. 272), escrevendo e inscrevendo outros textos com suas leituras, pois

onde o aparelho cientifico (o nosso) é levado a partilhar a ilusão dos poderes de que é necessariamente solidário, isto é, supor as multidões transformadas pelas conquistas e vitorias de uma produção expansionista, é sempre bom recordar que não se deve tomar os outros por idiotas (p. 273). 
Currículos prescritos porque não vividos apagam outras escritas, silenciam outras vozes, fixam os significados (LOPES, 2015, p.456), mas não param o mundo. Ameaçam a diversidade como valor social (ANPED; ABDC, 2015), mas não anulam a diferença, pois, em nome de outras escritas, decifrando-se a si mesmos, estudantes ocuparam as escolas e gritam que a escola é deles (SÜSSEKIND, PELLEGRINI, 2016a; 2016b). Vale lembrar, ao pensar nessas políticas, que a BNCC e a reforma do EM possuem vínculos inseparáveis com os testes externos padronizados, o material didático apostilado e uniformizado, a formação de professores com caráter gerencial-tecnicista (SÜSSEKIND, 2014b) e currículos conteudinais mercadológicos. Ou assumimos que currículos são criados cotidianamente como conversas complicadas (SÜSSEKIND, 2017) entre todas as formas de conhecimento, não só aqueles associados à Ciência ou à erudição. Assim, os currículos podem ser considerados também tessituras de experiências, processos de recriação/escritura permanente dos próprios conhecimentos, que têm suas histórias, e das pessoas e da própria sociedade. Na vida cotidiana, que é sempre plural, nas escolas, tecendo redes de conhecimentos e subjetividades (SANTOS, 2001) os currículos criados com professores e estudantes convocam experiências sociais e nesse sentido podem ser espaços-tempos de emancipação social, democracia e justiça cognitiva.

Por isso, desde 1980. com uma primeira crítica ao modelo científico e anunciando sua forma de ver e entender o mundo, Boaventura Santos sustentou que o modelo hegemônico da Ciência Moderna é oriundo de um modelo de racionalidade que se constituiu a partir da Revolução Científica do século XVI, e que alcançou seu apogeu no século XIX. Trata-se de um modelo de conhecimento que se baseia na formulação de leis gerais, e cujo campo de atuação parecia restrito ao âmbito das Ciências Naturais, mas que colonizou as outras possibilidades cientificas e provocou apagamentos e assassinatos de outros conhecimentos não ou pré-científicos - os epistemicídios. Ao mesmo tempo em que provocava epistemicídios e se fortalecia como formato único de conhecimento, indolente, arrogante, a tradição hegemônica da Ciência era questionada de dentro pelas ideias de relatividade, caos e complexidade, que visitam muito raramente os currículos escolares. Trata-se de ir além da visão que a própria Ciência faz dela mesma como algo que é “objetivo, factual e rigoroso" (OLIVEIRA, 2006, p. 35) e que sequestrou do conhecimento a experiência, os sentimentos humanos para que se possa caminhar no sentido de criar novos conhecimentos - prudentes - menos assimétricos e mais ecológicos.

Apontamos, aqui, o quanto a Ciência Moderna tem contribuído na produção de ignorâncias e invisibilidades, sendo o conhecimento escolar uma importante vítima desse epistemicídio. Seja na ideia de que currículos são documentos fixos ou mesmo na ideia de que é uma área em que técnicas gerais podem ser desenvolvidas no sentido de aprimorar a prática (como algo subalternizado pela teoria), ou que se pode fazer experiências controladas. $\mathrm{Ou}$, ainda, na obsessão pela elaboração de materiais iluminados pelos acadêmicos e suas ideias super-científicas, que a priori são tão bons que "servem" a qualquer 
sala de aula de qualquer lugar a qualquer tempo. Também são abissais quando chamados na defesa de conteúdos revolucionários e desalienantes. Ou, ainda, nas pesquisas que, ao entenderem a parte pelo todo, aplicarem modelos fixos, produzindo conhecimentos apenas sobre o que é ausente e ruim (conforme já abordamos em SÜSSEKIND, 2014a; SÜSSEKIND; PRESTES, 2015; SÜSSEKIND; PELLEGRINI, 2016a).

Pois é nesse sentido que as reformas são malévolas. Alimentam-se de soluções impossíveis, pregam resultados intangíveis, usando a falsidade como verdade alternativa (SANTOS, 2019). Malévola, fabricante de Fake News como o assédio ideológico e os privilégios da classe de professores, nutrindo-se das imagens dos espelhos (SANTOS, 2001; SÜSSEKIND; PRESTES, 2015), que apagam a vida e a criação nas escolas e sugerem que a educação enfrente uma grave crise e seja ruim. Malévolas, as reformas da BNCC e EM vendem a solução para o problema que fabricam. O modo de produção indolente e abissal não existe isoladamente à arrogância e, mais, ambos se aliam para produzir ignorâncias, invisibilidades e inexistências com eficácia. Por exemplo, ao considerarmos que tudo o que se cria nos cotidianos não existe nos números, nos índices, em muitas metodologias de pesquisas e mesmo como conhecimento curricular, ou seja, se considerarmos que o que acontece numa sala de aula (SÜSSEKIND, 2017) não é reconhecido como currículos por essas políticas que valorizam abissais. Isso porque elas valorizam ou reconhecem ou tornam existentes apenas os conhecimentos prescritos de fora das escolas, nos testes, nos livros didáticos e na BNCC/BNCC-EM por especialistas que não estão nos chãos das escolas, conforme as associações cientificas vêm criticando (ANPEd, 2018; ANPEd; ABdC, 2015; 2016; 2018).

A ignorância malévola priva a democracia (a sociedade em geral e os gestores públi$\cos$ ) dos fatos, percepções e opiniões. Expandindo ao máximo sua indolência e arrogância produz o esquecimento da função intelectual da docência, subalterniza a inteligência e autonomia intelectual de estudantes e subjuga a educação ao lugar de maquinaria social. Assim, a arrogância malévola se torna possível numa sociedade saturada pela fé no monopólio da verdade científica, sendo assim vulnerável a qualquer falsidade que se apresente como verdade alternativa e use os mecanismos da fé, por exemplo, em relação à questão de gênero. Sabemos, que o ministro da Educação, Mendonça Filho, afirmou durante a cerimônia de homologação da versão final da BNCC pelo presidente Michel Temer que "A base é plural, respeita as diferenças, respeita os direitos humanos, não há nenhuma prisão à ideologia de gênero ou coisa parecida". Isso é Fake News. A reforma fere a LDB/9394-96 em diversos artigos, notadamente os Art $3^{\circ}$ e 15, que garantem liberdade aos professores, autonomia pedagógica às escolas e compromisso com a formação na, com e para a diversidade (BRASIL, 1996). O manifesto das associações reforça a denúncia.

Cabe reforçar: não há base material que sustente as alterações feitas na LDB ou na BNCC para escolha de trajetórias pelos estudantes. Quem definirá as trajetórias são as condições de oferta dos sistemas, como ficou, de fato, estabelecido na Lei 
13.415/17, e isto marcará profundamente o ensino médio como o campo da desigualdade oficial para as juventudes brasileiras. Não há garantias de que os sistemas educacionais consigam cumprir com a parte diversificada. A oferta de todos os itinerários formativos certamente não vai acontecer, os estudantes não terão a possibilidade da escolha como tem sido anunciado, ficarão restritos às possibilidades de oferta das escolas, conforme o ocorrido quando a lei 5692/71 tornou obrigatória a profissionalização simultânea à formação geral em todas as escolas e, poucos anos depois, teve que ser alterada pela absoluta impossibilidade do sistema educacional de dar conta da referida obrigatoriedade (ANPEd, 2018).

Indolentes, as reformas recusam-se a reconhecer as realidades múltiplas e profundas adversidades do sistema nacional de educação. Malévola, a reforma do EM oferece uma flexibilização que unifica, uma igualdade que hierarquiza. Malévola, em sua metonímia, toma tudo pela parte, por isso, há apenas uma lógica que governa tanto o comportamento do todo como o de cada uma das suas partes. Há, pois, nessa lógica, uma suposta homogeneidade entre o todo e as partes e estas não têm existência fora da relação com a totalidade. Jogam-se as diferenças para o abismo, encurtando as possibilidades democráticas nas escolas.

A forma mais acabada de totalidade para a razão metonímica é a dicotomia, porque combina, do modo mais elegante, a simetria com a hierarquia (SANTOS, 2001; 2005), assim, numa associação malévola vingam as escolas charter, voucher, militarizadas, domésticas e tudo o mais, que esvaziam o público da educação pública. Como diz Santos, essas ignorâncias contribuem para que a democracia perca intensidade e as reformas não só esvaziam a condição de autonomia e participação das salas de aula, das comunidades escolares, dos professores, dos projetos político-pedagógicos. como negligenciam que as exigências locais são prioridade, porque são o que realmente existe. Mas a ignorância malévola sobrevive do epistemicídio, da antidemocracia e da desigualdade.

No aspecto legal e executivo, é preciso enfrentar o duelo entre as exigências e as condições que foi deflagrado pelas políticas curriculares da Reforma-BNCC-Diretriz-EM. Numa sociedade democrática, conforme entendemos na previsão da LDB, as exigências locais são prioridade em relação às suas condições. As comunidades escolares possuem direitos e, entre eles, está o de superar as condições (de desigualdade) locais. Nesse sentido, as condições, quando desfavoráveis, se tornam exigências e não o contrário. Logo, o caminho da reforma curricular não deve partir das condições, mas das exigências locais (SÜSSEKIND, FERNANDES, 2018, p. 50).

\section{O direito a sermos iguais}

Concluindo, a partir da afirmação do direito à diferença (que considero importante contribuição de Boaventura Santos para pensar as relações entre currículos, conhecimentos e cotidianos escolares), deslocamos o debate sobre as reformas, buscando argumentar contrariamente a unificação e homogeneização, maquinadas pela racionalidade gerencial 
capitalista de modo malévolo. Contra a ideia de controle curricular e intencionalidade dos conhecimentos e das aprendizagens/ensinagens, também vimos nos insurgindo em movimentos de contestação da linearidade, da prolepsia, da neutralidade e da totalidade, contra o pensamento único, desconstruindo a história única, lutando contra os uníssonos. Advogando pela desconstrução da hegemonia da teoria e a falácia de harmonia nos currículos, temos evocado relações ecológicas entre saberes que exigem o apreço ao dissenso e, certas vezes, movimentos de arqueologia das ausências, para serem produzidos como existentes novamente, por meio da crítica da razão indolente.

O primeiro descentramento provocado por essa crítica é que há uma produção das invisibilidades e de como isso afeta, cotidianamente, nossas vidas, escritas e identidades, (im)possibilidades e os currículos, a partir de como lidamos com a diferença. Reconhecer a abissalidade é entender que a diferença é cultural e socialmente construída e muitas vezes ditada, abissalmente imprimida como mapa de vida "pelo Norte" binário, hierarquizando e distanciando, numa perspectiva de normatização, em que nós professores somos, na criação curricular, vítimas e algozes.

O segundo deslocamento é das linhas de abissalidade, num movimento de inundar o mundo e as escolas com pensamentos pós-coloniais que valorizem as experiências, os saberes locais, nativos, tradicionais, de gênero, étnicos, e outros mais, que emerjam no enfrentamento da razão indolente. Essa que generaliza estudantes, invisibiliza os conhecimentos de professores ao taxá-los de reprodutores, exacerbando o papel da ciência e da técnica no que se refere a entender e praticar currículos em escolas. Contra o pensamento único e desumanizador, que aniquila a diferença, respondemos, com as epistemologias do Sul.

A ecologia dos saberes é um conjunto de epistemologias que partem da possibilidade da diversidade do mundo e da existência de redes de conhecimentos e subjetividades que atuam num movimento de globalização contra hegemônica (SANTOS, 2006). Essas epistemologias, ao provocarem o descentramento do Norte destacam dois pressupostos: primeiro, não há epistemologias neutras e as que clamam sê-lo são as menos neutras; segundo, a reflexão epistemológica deve incidir nas práticas de conhecimento e seus impactos noutras práticas sociais. Ou seja, se por um lado reconhecemos a diversidade epistemológica do mundo, por outro, desinvisibilizamos as práticas abissais do mesmo mundo desenhadas pela hegemonia científica do norte colonial, patriarcal e capitalista (SANTOS, 2013, p. 13).

Antes do deslocamento para o Sul epistemológico, da emergência dos pós-estruturalismos e das decolonialidades, a questão da pluralidade interna da Ciência foi suscitada sobretudo pelas epistemologias feministas, pelos estudos sociais e culturais da Ciência e pelas correntes da História e da Filosofia da Ciência. Como já tratamos em trabalhos anteriores (2007; 2012; 2015), questões como a relação pesquisador-objeto/sujeito de pesquisa, assim como a neutralidade da Ciência, vieram tornando explícita a dependência da atividade de investigação científica (de escolhas sobre os temas, os problemas, 
os modelos teóricos, as metodologias) de seus financiamentos. E, por via desses, sublinhamos já também a íntima relação entre o desenvolvimento de estudos científicos e os diferentes modos de relacionamento dos cientistas com contextos institucionais, com seus pares, o Estado, as entidades financiadoras, os interesses econômicos ou o interesse bélico. Com a ajuda das obras de Bourdieu (2004) e Hobsbawn (1995), finalmente, entregamo-nos à tarefa de interrogar as condições e os limites da autonomia das atividades científicas em relação ao contexto social e cultural em que ocorrem e adensamos sua conceituação a partir de uma lógica de colonização da diferença que chamamos indolente, arrogante e malévola (SANTOS, 2001; 2004; 2010; 2019; SÜSSEKIND, 2007; 2012; 2014a; 2014b; 2015).

Tudo isso, para admitirmos que as linhas abissais que desenham as políticas curriculares atuais agem coisificando os conhecimentos, ferindo a autonomia e desumanizando o trabalho docente e, ainda, descaracterizand o o estudante na sua condição de diferente, de outro legítimo. Compreendendo o humano como diverso, defendemos que o esforço de unificação dos resultados de aprendizagens é diretamente responsável pela produção dos resultados ruins, demonização dos professores e desvalorização da educação democrática (SÜSSEKIND, 2014a; SÜSSEKIND; FERNANDES, 2019). Currículos e testes padronizados tratam o trabalho docente sob a expectativa de reprodução, de desumanização, de modo que "os produtos do trabalho se tornam mercadorias, coisas sociais, com propriedades perceptíveis e imperceptíveis" (MARX, 1977, p. 80). Na direção do Sul epistemológico, concluímos que conhecimento curricular que se deseja democrático é deslocamento e por isso é uma conversa, complicada e "dissensuosa", que desse modo se faz resistência permanente ao pensamento único, homogêneo, unívoco, uníssono. Dado que não é comum, é diferença e é dissenso, e existe pralém do desejo de controle e do esforço de aniquilação.

Recebido em: 06/06/2019 e aprovado em: 17/06/2019

\section{Notas}

1 Para Santos, muito mais que regiões geográficas, o Sul (global) é por exclusão tudo o que não é o Norte (branco, masculino, ocidental, heterossexual, colonial). O Norte global é europeu e americano.

2 Em acordo ao mesmo autor (SANTOS, 2001; 2007; 2010) sublinhamos que o potencial de aprendizado do Norte global se amplia, enriquece e democratiza ao reconhecer a globalidade do Sul. 


\section{Referências}

ALVES, N. Sobre movimentos das pesquisas nos/dos/com os cotidianos. In: OLIVEIRA, I. B.; ALVES, N. A Pesquisa nos/dos/com os cotidianos das escolas sobre redes de saberes. Rio de Janeiro: DP et Alii, 2008.

ALVES, N. Decifrando o pergaminho - o cotidiano na escola nas lógicas das redes cotidiana In: OLIVEIRA, I. B. de.; ALVES, N. Pesquisa no/do cotidiano das escolas, sobre redes de saberes. Rio de Janeiro: DP\&A, p.13-38 2001.

ANPED. BNCC do Ensino Médio: alguns pontos para o debate. Maio, 2018. Disponível em: http:// www.anped.org.br/news/nota-anped-proposta-de-bncc-do-ensino-medio-alguns-pontos-para-odebate. Acesso em: 05.jun.2019.

ANPED; ABDC. Ofício n.o 01/2015/GR: Exposição de Motivos sobre a Base Nacional Comum Curricular. Rio de Janeiro, 9 de novembro de 2015. Disponível em: $<$ http://ced.ufsc.br/files/2015/10/ Exposi\%C3\%A7\%C3\%A3o-de-Motivos-a-BNCC-ANPED-e-ABdC.pdf>. Acesso em: 05.jun. 2019.

BAUMAN, Z. Modernidade e Ambivalência, Rio de Janeiro, Zahar, 1999.

BAUMAN, Z. O Mal-estar da Pós-Modernidade, Rio de Janeiro, Zahar, 1998.

BOURDIEU, P. Os Usos Sociais da Ciência: Por uma sociologia clínica do campo científico. São Paulo: Editora Unesp, 2004.

BRASIL. Base Nacional Comum Curricular. Quarta versão. Brasília: MEC/SEB, 2017.

BRASIL. Lei no 9.394/96, de 20 de dezembro de 1996. Disponível em: <http://www.planalto.gov.br/ ccivil_03/leis/19394.htm>. Acesso em: 06 jun. 2019.

BRASIL. Plano Nacional de Educação PNE 2014-2024.Brasília: Inep, 2015.

BRASIL Lei no 9394, de 1996. Estabelece as diretrizes e bases da educação nacional. Lei № 9.394, de 20 de dezembro de 1996. Brasília: Diário Oficial da União, 20 dez. 1996. Disponível em: <http://www. planalto.gov.br/ccivil_03/leis/L9394.htm>. Acesso em: 07 jul. 2016.

BOBBIT, J. F. The Curriculum. Houghton Mifflin: Original de Harvard University, 1918.

CERTEAU, Michel de. A invenção do cotidiano. Artes de fazer. Rio de Janeiro: Vozes, 1994.

GIARD, L. História de uma pesquisa. In: CERTEAU, Michel de. A invenção do cotidiano: 1, Artes de fazer. Petrópolis: Vozes, p.9-32, 1994.

GIDDENS, A. As Consequências da Modernidade. UNESP: São Paulo, 2ª̣ ed., 1997.

HOBSBAWN, Eric. Feiticeiros e aprendizes: as ciências naturais. In: A Era dos Extremos: 0 breve século XX (1914-1991). São Paulo: Companhia das Letras, 1995. p. 504-536.

LOPES, A. C. Por um currículo sem fundamentos. Linhas Críticas, Brasília, UNB, v. 21, n. 45, p.445466, ago. 2015.

MARX, K. O Capital. Crítica da Economia Política. Livro 1. Vol. 1., 1a edição 1890. Rio de Janeiro: Ed. Civilização Brasileira, 1977.

OLIVEIRA, I. B. de. O Currículo como criação cotidiana. Rio de Janeiro: DP\&A, 2012. 
OLIVEIRA, I. B. Boaventura e a Educação. Belo Horizonte, Ed Autêntica, 2006

OLIVEIRA, I. B. de. Currículos praticados: entre a regulação e a emancipação. RJ: DP\&A, 2003.

OLIVEIRA, I. B. de.; SÜSSEKIND, M. L. Dimensões político-epistemológicas do equívoco conservador na educação: A base curricular brasileira no contexto dos currículos nacionais. Revista Portuguesa de Educação, 2018. Disponível em: https://revistas.rcaap.pt/rpe/article/view/14806/12563. Acesso em: 05.jun. 2019.

OLIVEIRA, I. B.; SÜSSEKIND, M. L. Das teorias críticas às críticas das teorias: Um estudo indiciário sobre a conformação dos debates no campo curricular no Brasil. Revista Brasileira de Educação, Minho, Instituto de Educação da Universidade do Minho, v. 22, n.71, 1-20, 2017. Acesso em 05/07/2019. Disponível em: https://revistas.rcaap.pt/rpe/article/view/14806

OLIVEIRA, I. B. de; SÜSSEKIND, M. L. Do tsunami conservador e resistência: a CONAPE em defesa da educação pública. Educação e Realidade, 2019, no prelo.

PINAR, W. F. Curriculum Studies in Brazil: Intellectual Histories, Present Circumstances. New York: Palgrave Macmillan, 2011.

SANTOS, Boaventura de S. A três ignorâncias: arrogante, indolente e malévola. Jornal de Letras, Lisboa, Caderno Ideias, p. 30, 13 a 26 mar., 2019.

SANTOS, Boaventura de S. Se Deus fosse um activista dos direitos humanos. Coimbra: Ed. Almedina, 2013.

SANTOS, Boaventura de S. Para além do pensamento abissal. In: SANTOS, Boaventura de S.; MENESES, M. P. (Orgs) Epistemologias do Sul. São Paulo: Cortez, 2010.

SANTOS, B. S. Para além do Pensamento Abissal: Das linhas globais a uma ecologia de saberes. Revista Crítica de Ciências Sociais, Coimbra, v. 78, n. 1, p.3-46, out. 2007.

SANTOS, B. S. A gramática do tempo: para uma nova cultura política. São Paulo: Cortez, 2006.

SANTOS, Boaventura de S. Semear outras soluções: Os caminhos da biodiversidade e dos conhecimentos rivais. Rio de Janeiro: Civilização Brasileira, 2005.

SANTOS, Boaventura de S. (Org.) Conhecimento prudente para uma vida decente: um discurso sobre as ciências revisitado. São Paulo: Cortez, 2004.

SANTOS, Boaventura de S. Crítica da razão indolente: contra o desperdício da experiência. São Paulo: Cortez, 2001.

SANTOS, Boaventura de S. Um discurso sobre as ciências. Porto: Afrontamento, v. 8, 1987.

SÜSSEKIND, M.L.; FERNANDES, M. D. E. Os debates sobre os currículos nacionais e a defesa da educação democrática. Linguagens, Educação e Sociedade, Teresina, UFPI, v. 24, n. 41, p. 40-57, 2019. Disponível em: $<$ https://ojs.ufpi.br/index.php/lingedusoc/article/view/8742/pdf>. Acesso em 05 jun. 2019.

SÜSSEKIND, M. L. O Que aconteceu na aula? Políticas, currículos e escritas nos cotidianos da formação de professores numa universidade pública. Teias, Rio de Janeiro, PROPEd/UERJ, v. 18, p. 134-148, 2017.

SÜSSEKIND, M. L. Currículo: contribuições de Boaventura de Sousa Santos e Michel de Certeau. In: FERRAÇO, C. E.; RANGEL, I; CARVALHO, J.; NUNES, K. (Orgs.). Diferentes perspectivas em currículo na atualidade. 1ed. Petrópolis: De Petrus et Alii: NUPEC/UFES, v. 1, p. 169-184, 2015. 
SÜSSEKIND, M. L. As (im)possibilidades de uma Base Comum Nacional. Revista e-Curriculum, PUCSP, São Paulo, 12(3), 151 -1529, 2014a.

SÜSSEKIND, M. L. Taking Advantage of the Paradigmatic Crisis: Brazilian Everyday Life Studies as a new epistemological approach to the understanding of teachers' work. Revista Citzenship, Social and Economics Education, Sage Journals, UK, v. 13, n. 3, p. 199-210, 2014b. Acesso: www.wwwords.co.uk/ CSEE/. Acesso: https://journals.sagepub.com/doi/pdf/10.2304/csee.2014.13.3.199. DOI: http://dx.doi. org/10.2304/csee.2014.13.3.199

SÜSSEKIND, M. L. Quem é William F. Pinar?. Rio de Janeiro: De Petrus et Alii, 2014c.

SÜSSEKIND, M. L. O Ineditismo dos Estudos nosdoscom os Cotidianos: Currículos e Formação De Professores, Relatos e Conversas em uma Escola Pública no Rio de Janeiro, Brasil. Revista e-Curriculum, PUCSP, São Paulo, v.9, p.1 - 21, 2012.

SÜSSEKIND, M. L. Teatro de Ações: arqueologia dos estudos nosdoscom os cotidianos - relatos de práticas pedagógicas emancipatórias, 235f. Tese (Doutorado em Educação), UERJ, RJ, 2007.

SÜSSEKIND, M. L.; PELLEGRINI, R. Não existe pecado do lado de baixo do equador: Políticas de currículo, direito à educação e as escritas nunca escritas. Cadernos de Pesquisa, São Luís, UFMA, v. 23, número especial, São Luís, p. 43-56, dez, 2016a.

SÜSSEKIND, M. L.; PELLEGRINI, R. "A escrita nunca escrita” ou por que (re)afirmamos nossa contrariedade à Base Comum. In. FRANGELLA, R. C. P. Currículo, formação e avaliação: redes de pesquisas em negociação. Curitiba: CRV, p.129-150, $2016 b$. 